\title{
Nanotechnology for Tissue Engineering Applications
}

\author{
Xiaojun Yu, ${ }^{1}$ Junping Wang, ${ }^{2}$ Yanan Du, ${ }^{3}$ Zuwei Ma, ${ }^{4}$ and Wei $\mathrm{He}^{5}$ \\ ${ }^{1}$ Department of Chemistry, Chemical Biology and Biomedical Engineering, Stevens Institute of Technology, Hoboken, NJ 07030, USA \\ ${ }^{2}$ Xylos Corporation, Langhorne, PA 19047, USA \\ ${ }^{3}$ Department of Biomedical Engineering, School of Medicine, Tsinghua University, Beijing 100084, China \\ ${ }^{4}$ RainDance Technologies Inc., Lexington, MA 02421, USA \\ ${ }^{5}$ McGowan Institute for Regenerative Medicine, University of Pittsburgh, Pittsburgh, PA 15219, USA
}

Correspondence should be addressed to Xiaojun Yu, xyu@stevens.edu

Received 26 May 2011; Accepted 26 May 2011

Copyright (C) 2011 Xiaojun Yu et al. This is an open access article distributed under the Creative Commons Attribution License, which permits unrestricted use, distribution, and reproduction in any medium, provided the original work is properly cited.

Due to the tissue and organ shortage, tissue engineering strategies combining engineering principles and methods and biological sciences in creating implantable tissues have been viewed as the most promising technologies for regenerating damaged tissues and organs. As native tissues or organs are composed of proteins within nanoscale and cells directly interact with nanostructured extracellular matrices (ECM), nanobiomaterials such as nanofibers, nanotubes, nanoparticles and other nanofabricated devices with smaller than $100 \mathrm{~nm}$ in at least one dimension are capable of contributing to cell growth and tissue regeneration.

The aim of this special issue is to demonstrate the latest achievement of nanotechnology and its development in tissue engineering field. The eleven research articles comprising this special issue cover topics including the fabrication, characterization, and application of nanobiomaterials. Research articles on biomaterial surface technology, cellbiomaterials interaction and nanobiomaterials properties are also included in this issue.

Electrospinning is a well-established technique aiming at producing ultrafine fibers by electrically charging a suspended droplet of polymer melt or solution. There are various kinds of materials that can be electrospun into nanofibrous structures, which have promising applications in tissue engineering. The first four papers of this special issue discussed the electrospinning technique for tissue engineering application. The first paper "Fabrication of biodegradable polyester nanocomposites by electrospinning for tissue engineering" reviewed several biodegradable polyesterbased nanocomposites for tissue engineering applications. The second paper "Electrospun collagen: a tissue engineering scaffold with unique functional properties in a wide variety of applications" specifically focused on the collagen-based electrospun nanomaterials with variable applications. The third paper "Quantitatively controlled fabrication of uniaxially aligned nanofibrous scaffold for cell adhesion" developed uniaxially aligned nanofibers via quantitatively controlled fabrication method. The fourth paper "Electrospinning of poly (ethylene-co-vinyl alcohol) nanofibres encapsulated with Ag nanoparticles for skin wound healing" achieved fabrication of an anti-inflammatory nanofibrous scaffold with the encapsulation of Ag nanoparticles in poly (ethylene-co-vinyl alcohol) nanofibers.

The following two papers are related to surface morphology and micropatterning technology. Specifically, the fifth paper "Dependence of spreading and differentiation of mesenchymal stem cells on micropatterned surface area" discussed the effect of micropatterning technology on the differentiation of Mesenchymal stem cells (MSCs). The sixth paper "Surface modification of titanium with heparin-chitosan multilayers via layer-by-layer self-assembly technique" showed a surface modification method via chitosan-heparin layerby-layer self-assembly technique.

In the seventh paper, "Particle size control of $1 / 2 \mathrm{O}_{3}: \mathrm{Eu}^{3+}$ prepared via a coconut water-assisted sol-gel method," a type of $\mathrm{Eu}^{3+}$-doped $\mathrm{Y}_{2} \mathrm{O}_{3}$ nanoparticle was produced through protein sol-gel technique and the adjustment of $\mathrm{pH}$ was tested in order to control the particle size of the powders. In the eighth paper, "BN nanoparticles $/ S i_{3} N_{4}$ wave-transparent composites with high strength and low dielectric constant," the addition of the $\mathrm{BNnp} / \mathrm{Si}_{3} \mathrm{~N}_{4}$ nanoparticles improved the dielectric properties of $\mathrm{BNnp} / \mathrm{Si}_{3} \mathrm{~N}_{4}$ composites and decreased the mechanical properties. The ninth and tenth papers "Analysis of carbon nanotubes on the mechanical 
properties at atomic scale" and "Some observations on carbon nanotubes susceptibility to cell phagocytosis" discussed the carbon nanotubes in terms of their mechanical properties and their susceptibility to cell phagocytosis. The eleventh paper "Enhanced photocatalytic activity for degradation of methyl orange over silica-titania" reported a method of constructing silica-modified titania (SMT) powders with enhanced photocatalytic activity.

\section{Acknowledgments}

The editors appreciate all the authors and coauthors of these articles comprising the special issue for their scientific contribution. Moreover, the editors would like to express their thanks to all the reviewers for their effort and dedication. They hope that this special issue will attract a wide range of the readers who are working or will join this challenging and fast-developing field and continuously motivate their research and work.

Xiaojun Yu

Junping Wang

Yanan Du

Zuwei Ma

Wei He 

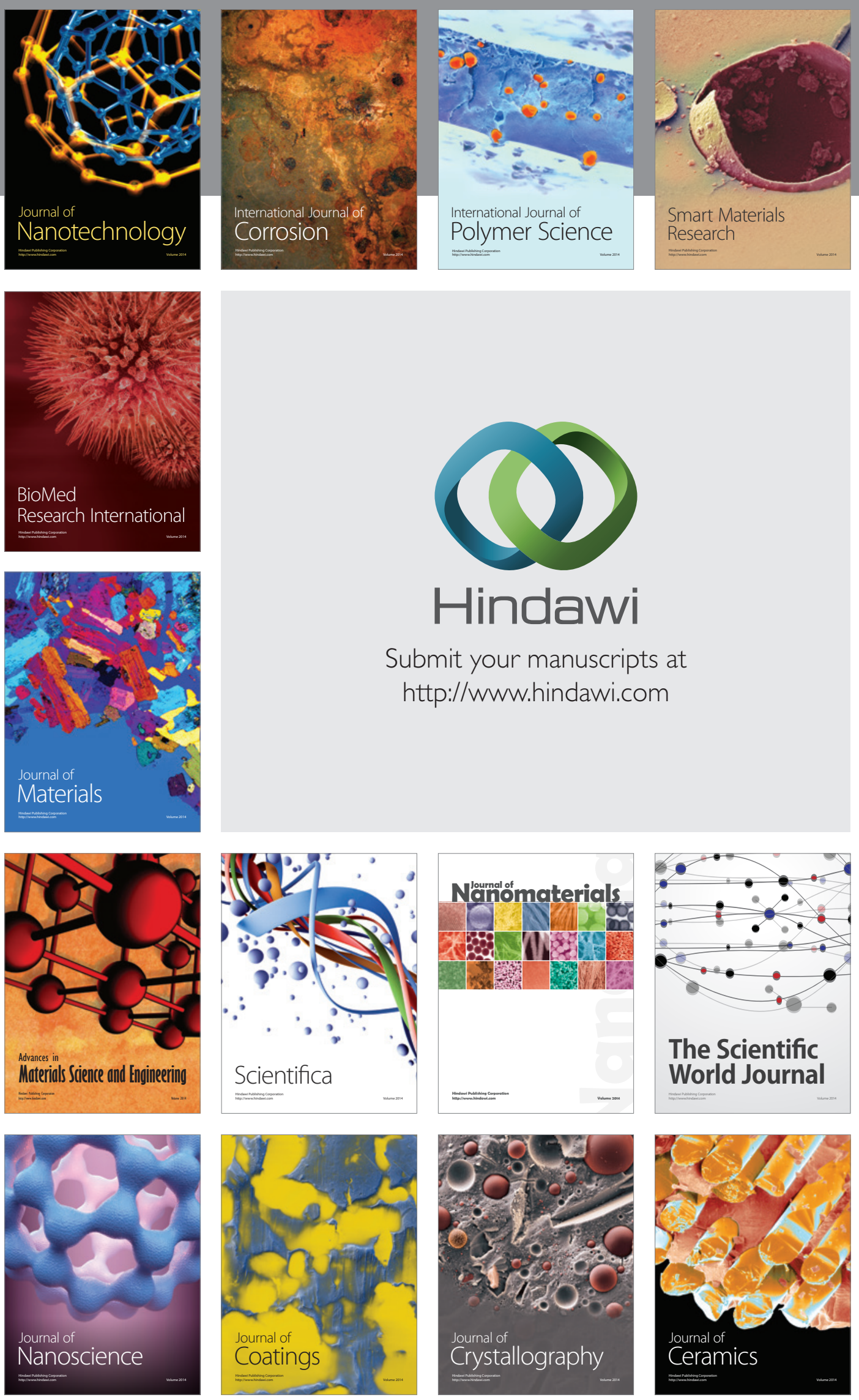

The Scientific World Journal

Submit your manuscripts at

http://www.hindawi.com

\section{World Journal}

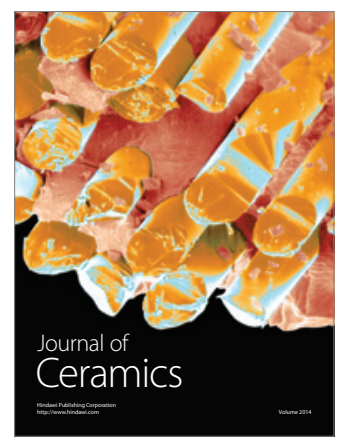

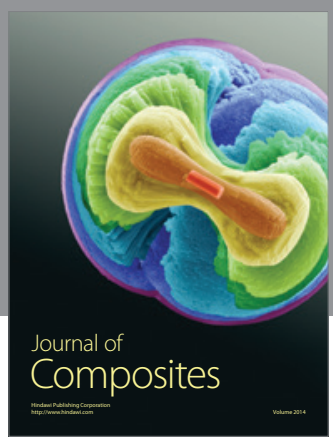
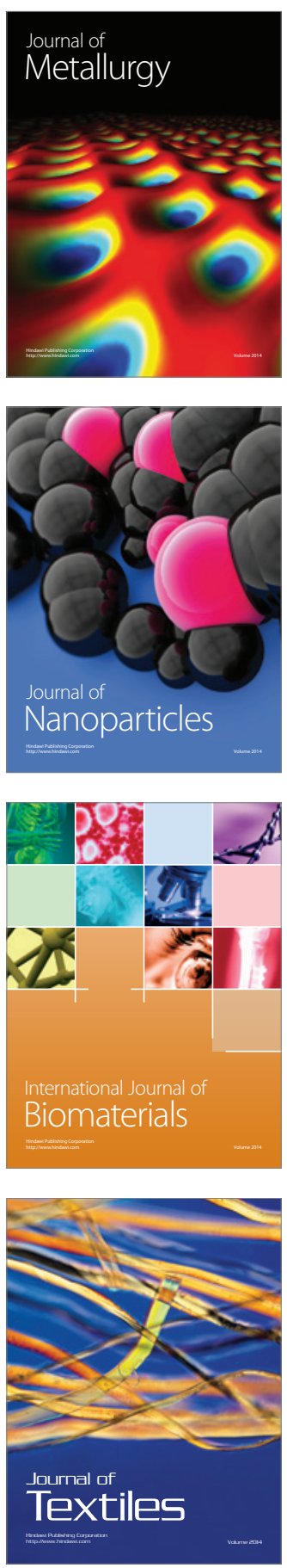